\title{
DNA-PKcs modulates progenitor cell proliferation and fibroblast senescence in idiopathic pulmonary fibrosis
}

David M. Habiel ${ }^{1 \dagger}$, Miriam S. Hohmann ${ }^{1^{* \dagger}} \mathbb{D}$, Milena S. Espindola', Ana Lucia Coelho ${ }^{1}$, Isabelle Jones ${ }^{1}$, Heather Jones ${ }^{1}$, Richard Carnibella ${ }^{2}$ Isaac Pinar ${ }^{2}$, Freda Werdiger ${ }^{2}$ and Cory M. Hogaboam ${ }^{*}$

\begin{abstract}
Background: Recent studies have highlighted the contribution of senescent mesenchymal and epithelial cells in Idiopathic Pulmonary Fibrosis (IPF), but little is known regarding the molecular mechanisms that regulate the accumulation of senescent cells in this disease. Therefore, we addressed the hypothesis that the loss of DNA repair mechanisms mediated by DNA protein kinase catalytic subunit (DNA-PKcs) in IPF, promoted the accumulation of mesenchymal progenitors and progeny, and the expression of senescent markers by these cell types.

Methods: Surgical lung biopsy samples and lung fibroblasts were obtained from patients exhibiting slowly, rapidly or unknown progressing IPF and lung samples lacking any evidence of fibrotic disease (i.e. normal; NL). The expression of DNA-Pkcs in lung tissue was assessed by quantitative immunohistochemical analysis. Chronic inhibition of DNA-PKcs kinase activity was mimicked using a highly specific small molecule inhibitor, Nu7441. Proteins involved in DNA repair (stage-specific embryonic antigen (SSEA)-4 $4^{+}$cells) were determined by quantitative Ingenuity Pathway Analysis of transcriptomic datasets (GSE103488). Lastly, the loss of DNA-PKc was modeled in a humanized model of pulmonary fibrosis in NSG SCID mice genetically deficient in PRKDC (the transcript for DNAPK(s) and treated with Nu7441.
\end{abstract}

Results: DNA-PKcs expression was significantly reduced in IPF lung tissues. Chronic inhibition of DNA-PKcs by Nu7441 promoted the proliferation of SSEA4 ${ }^{+}$mesenchymal progenitor cells and a significant increase in the expression of senescence-associated markers in cultured lung fibroblasts. Importantly, mesenchymal progenitor cells and their fibroblast progeny derived from IPF patients showed a loss of transcripts encoding for DNA damage response and DNA repair components. Further, there was a significant reduction in transcripts encoding for PRKDC (the transcript for DNA-PKCS) in SSEA4 ${ }^{+}$mesenchymal progenitor cells from IPF patients compared with normal lung donors. In SCID mice lacking DNA-PKcs activity receiving IPF lung explant cells, treatment with Nu7441 promoted the expansion of progenitor cells, which was observed as a mass of SSEA4 $4^{+} \mathrm{CgA}^{+}$expressing cells.

Conclusions: Together, our results show that the loss of DNA-PKCs promotes the expansion of SSEA4 ${ }^{+}$ mesenchymal progenitors, and the senescence of their mesenchymal progeny.

Keywords: DNA-PKcs, Mesenchymal progenitor cells, Senescence, IPF

\footnotetext{
* Correspondence: miriam.hohmann@cshs.org; cory.hogaboam@cshs.org ${ }^{\dagger}$ David M. Habiel and Miriam S. Hohmann contributed equally to this work. 'Department of Medicine, Cedars-Sinai Medical Center, Women's Guild Lung Institute, 127 S San Vicente Blvd., AHSP A9315, Los Angeles, CA 90048, USA Full list of author information is available at the end of the article
}

(c) The Author(s). 2019 Open Access This article is distributed under the terms of the Creative Commons Attribution 4.0 International License (http://creativecommons.org/licenses/by/4.0/), which permits unrestricted use, distribution, and reproduction in any medium, provided you give appropriate credit to the original author(s) and the source, provide a link to the Creative Commons license, and indicate if changes were made. The Creative Commons Public Domain Dedication waiver (http://creativecommons.org/publicdomain/zero/1.0/) applies to the data made available in this article, unless otherwise stated. 


\section{Background}

Interstitial lung diseases (ILD) are a group of diseases characterized by interstitial fibrosing of the lungs leading to the loss of alveolar function and normal gas exchange [1]. Idiopathic pulmonary fibrosis (IPF) is the most common form of ILD, with a median survival of 2-3 years after diagnosis [2] and limited therapeutic options. Currently, IPF patients are treated with OFEV or Esbriet, both of which slow down the progression of this disease, but many patients ultimately require lung transplantation despite treatment with these drugs. Most IPF patients that succumb to this disease die due to respiratory failure, however approximately $23 \%$ of these patients succumb due to non-respiratory causes, including ischemic heart failure, bronchogenic carcinoma, infection and pulmonary embolism [2]. Several studies have examined mechanisms leading to disrepair in IPF lung tissues and prevailing mechanisms suggest that epithelial dysfunction and/or progenitor cell abnormalities leads to chronic and aberrant activation of mesenchymal cells that are paramount to disrepair in lung fibrosis [3-5]. In line with this, a subpopulation of cells expressing the stage-specific embryonic antigen (SSEA)-4 with the properties of mesenchymal progenitors were identified in the lungs of IPF patients and shown to be "diseasemediating" [6]. Unlike their normal counterparts, IPF mesenchymal progenitor cells produce daughter cells that manifest the full spectrum of IPF hallmarks, including the ability to form fibrotic lesions in vivo [6]. Interestingly, in cancer, progenitor cells also have pathological roles by dividing asymmetrically and producing malignant daughter cells [7]. Although mesenchymal progenitor cells mediate repair and regeneration in response to injury, in IPF these cells may actually contribute to disrepair and disease progression.

Several studies have identified the relationship between DNA damage, DNA repair, and pulmonary fibrosis [8]. In fact, we have recently reported that loss of clusterin protein promoted disrepair and senescence in fibrotic lungs via the loss of DNA damage response and repair pathways [9]. DNA-dependent protein kinase catalytic subunit (DNAPKcs), a member of the PI3K related family of enzymes, is a master regulator of the DNA-damage response [10]. DNA$\mathrm{PK}$ is a complex of three proteins, consisting of Ku70/Ku80 and the catalytic holoenzyme DNA-PKcs, and is activated upon binding of Ku70/Ku80 and DNA. Activation induces its autophosphorylation as well as the phosphorylation of several other proteins that culminates in cell cycle checkpoint activation and DNA repair [11, 12]. DNA-PKcs is also integral to NHEJ DNA repair, VD-J recombination, antiviral responses against DNA viruses, innate DNA sensing and in telomere maintenance [11-13]. Given the importance of this protein in DNA double strand break repair and cell cycle checkpoint, many studies have assessed its role in tumorigenesis. It has been shown that the kinase activity of DNA-PKcs can act as a negative regulator of p53-mediated CDKN1A transcription in stressed cells, and subsequently promoting apoptosis of the affected cells [14]. However, DNA-PKcs mediated NHEJ repair was observed to promote radiation resistance of various tumor cells [15]. Considering our previous data showing the relevance of DNA damage and loss of DNA damage repair pathways in disrepair and senescence in fibrotic lungs [9] and the divergent activities of DNA-PKCs in physiological and pathological settings, the objective of this study was to investigate the role of DNA-PKcs in IPF and lung fibrosis.

In this study we expand upon our previous observations and demonstrate the loss of DNA-PK in IPF lung tissues compared to nonfibrotic lungs. The expression of DNA-PKcs was rarely detected in the nuclei of IPF mesenchymal cells and it did not colocalize with hypomethylated CpG DNA (CpG), nor did it regulate CpGmediated myofibroblast differentiation in normal or IPF lung fibroblasts. Chronic inhibition of DNA-PKcs kinase activity using a highly specific small molecule inhibitor, $\mathrm{Nu} 7441$ [16] promoted the expansion of SSEA4 ${ }^{+}$mesenchymal progenitor cells and a significant increase in the expression of myofibroblast, senescence-associated and inflammatory markers in cultured lung fibroblasts. Importantly, mesenchymal progenitor cells and their fibroblast progeny derived from IPF patients showed a loss of transcripts encoding for DNA damage response and DNA repair components. Further, there was a significant reduction in transcripts encoding for PRKDC (the transcript for DNA-PKCs) in SSEA4 $4^{+}$mesenchymal progenitor cells from IPF patients compared with normal lung donors. Transcriptomic, flow cytometric and immunofluorescence analysis suggested that SSEA4 ${ }^{+}$ mesenchymal progenitor cells expressed the neuroendocrine marker, CgA. In a humanized SCID mouse model of IPF [17], treatment with Nu7441 promoted the expansion of mesenchymal progenitor cells (observed as a mass of SSEA4 ${ }^{+} \mathrm{CgA}^{+}$expressing cells). Collectively, our results suggest that DNA-Pkcs expression is decreased in the lungs of IPF patients and its loss promotes the expansion of mesenchymal progenitor cells and increased expression of senescent markers in mesenchymal cells.

\section{Methods}

\section{Patient samples and primary lung fibroblasts}

Normal and IPF surgical lung biopsy samples and lung fibroblasts were obtained as previously described $[17,18]$. Both normal and IPF lung fibroblasts were obtained by mechanically dissociating lung biopsy specimens or explants into sterile tissue culture plates and pipetting at least 10 times in complete medium [Dulbecco's modified Eagle's medium (DMEM; Lonza, 
Basel, Switzerland) plus 15\% fetal bovine serum (Atlas Biologicals, Inc., Fort Collins, CO), $100 \mathrm{IU}$ of penicillin, $100 \mu \mathrm{g} / \mathrm{mL}$ of streptomycin (Mediatech, Manassas, VA), $292 \mu \mathrm{g} / \mathrm{mL}$ of l-glutamine (Mediatech), and $100 \mu \mathrm{g} / \mathrm{mL}$ of Primocin (InvivoGen, San Diego, CA)]. Cells were maintained at $37^{\circ} \mathrm{C}$ and $10 \% \mathrm{CO}_{2}$ and medium was changed twice a week by carefully aspirating the liquid, retaining the minced tissues in the flask, and replacing with fresh medium. This process was repeated until stromal colonies were apparent (1 to 2 weeks), after which the colonies were trypsinized and passaged 4 to 5 times and fibroblast purity was confirmed by flow cytometry and/or real-time quantitative PCR analysis for CD45, EpCAM, and CD31.

Normal lung fibroblasts were derived from nonfibrotic lung samples lacking any evidence of disease. Patients were diagnosed with IPF using a multidisciplinary, clinical, radiological, and pathological mechanism [19]. The physiological criteria used to validate disease progression during the first year of follow-up included a forced vital capacity (FVC) decrease of greater than or equal to $10 \%$ and a diffusing capacity for carbon monoxide (DLCO) decrease of greater than or equal to $15 \%$ based on baseline physiological abnormality. Baseline data for each patient in the study included detailed clinical assessment, physiological studies, high-resolution computed tomography (HRCT), and surgical lung biopsies (SLBs).

\section{Cells and cell culture condition}

Lung fibroblasts were cultured in complete medium at $37^{\circ} \mathrm{C}$ and $10 \% \mathrm{CO}_{2}$. Medium was changed twice a week and cells were passaged when $70-90 \%$ confluency was reached. For transcriptomic experiments, $2.5 \times 10^{5}$ lung fibroblasts per well were plated in complete medium into a 6-well plate overnight at $37^{\circ} \mathrm{C}$ and $10 \% \mathrm{CO}_{2}$. Cells were then stimulated with $10 \mu \mathrm{M} \mathrm{CpG}$ (Hycult Biotech) and/or treated with $500 \mathrm{nM} \mathrm{Nu} 7441$ (Selleckchem.com) for $24 \mathrm{~h}$ (acute) or once every 3 days for a total of 25 days. After treatment, images of the cultured cells were acquired using an EVOS FL inverted microscope at 20x magnification (Thermo Fisher Scientific). Cells were then trypsinized for Flow Cytometry or lysed by Trizol ${ }^{\mathrm{m}}$ (Thermo-Fisher Scientific) for qPCR analysis as described. For studies assessing Collagen 1, IL-8, IL-1ß and aSMA protein expression, cells were then stimulated with $10 \mu \mathrm{M} \mathrm{CpG}$ (Hycult Biotech), $20 \mathrm{ng} / \mathrm{ml}$ recombinant TGFß1 (R\&D systems) and/or treated with $500 \mathrm{nM}$ of Nu7441 (Selleckchem.com) for 24 or $72 \mathrm{~h}$.

\section{Immunohistochemistry}

Lung tissue was fixed in 10\% NBF solution for $24 \mathrm{~h}$ and subsequently transferred into tissue cassettes and kept in a $70 \%$ ethanol solution for approximately $24 \mathrm{~h}$. Lungs were then processed using routine histology techniques.
Sections $(4 \mu \mathrm{m})$ were deparaffinized, hydrated and subjected to antigen retrieval in $10 \mathrm{mM}$ Citric acid solution (pH 6.0). Samples were then stained with rabbit antiDNA-PKcs monoclonal antibody (Clone Y393, Abcam) or rabbit anti-CgA polyclonal antibodies (Abcam) overnight at $4{ }^{\circ} \mathrm{C}$ and processed as previously described [9]. Images were obtained using Zeiss Axio Observer Z1 microscope and the Zeiss Zen 2012 v 1.1.2.0 software (Zeiss) or ScanScope AT System. The quantification of DNA-PKcs expression (Integrated Optical Density) was performed using Image-Pro Premier software.

\section{Immunofluorescence analysis}

Lung fibroblasts were plated onto Lab-Tek II Chamber Slides (Fisher Scientific) and stimulated with $1 \mu \mathrm{M}$ biotinylated-CpG (Biotin-CpG; InvivoGen) for $24 \mathrm{~h}$ at $37^{\circ} \mathrm{C}$ and $10 \% \mathrm{CO}_{2}$. Cells were then washed with DPBS and fixed with $4 \%$ paraformaldehyde solution for $10 \mathrm{~min}$ at room temperature. Paraformaldehyde was then washed, and the cells were permeabilized using $0.5 \%$ TritonX100 in DPBS for $10 \mathrm{~min}$ at room temperature, washed and blocked using antibody dilution/blocking solution (DPBS $+2 \%$ bovine serum albumin $+2 \%$ normal goat serum $+0.025 \%$ sodium azide) for $30 \mathrm{~min}$ at room temperature. Cells were then incubated with rabbit antihuman-DNA-PKcs monoclonal antibody (Clone Y393, Abcam) or IgG control antibody overnight at $4{ }^{\circ} \mathrm{C}$, then washed and incubated with 1:500 diluted Alexa-flour 488-conjugated anti-rabbit (Thermo Fisher Scientific) and 1:500 diluted Alexa-flour 594-conjugated streptavidin (Thermo Fisher Scientific) for 1 hour at room temperature. Cells were then washed three times with DPBS and mounted with ProLong Gold Antifade Mountant with DAPI (Thermo Fisher Scientific). For human lung tissues, paraffin embedded tissues were deparaffinized, rehydrated and subjected to antigen retrieval in $10 \mathrm{mM}$ Citric acid solution ( $\mathrm{pH}$ 6.0). Slides were then permeabilized using a $10 \%$ methanol solution, blocked and stained using anti-SSEA4 and CgA antibodies (Abcam) overnight at $4{ }^{\circ} \mathrm{C}$. As control, IgG isotype antibodies were utilized on serial sections from the same tissue. The next day, slides were washed three times with DPBS and once with DPBS containing 0.05\% Tween-20 (DPBS-T), incubated with Alexa-Flour 594 conjugated anti-mouse and Alexa-Flour 488 conjugated anti-rabbit secondary antibodies (Thermo Fisher Scientific) for $1 \mathrm{~h}$ at room temperature. Slides where then washed three times with DPBS and once with DPBS-T and mounted with ProLong Gold Antifade Mountant with DAPI (Thermo Fisher Scientific). A Zeiss Axio Observer Z1 microscope and the Zeiss Zen 2012 v 1.1.2.0 software (Zeiss) were used to obtain representative images and fluorescence intensity was set based on the 
background fluorescence levels observed in the IgG stained samples.

\section{Quantitative PCR analysis}

Cells were lysed in Trizol $^{\text {Tim }}$ reagent (Thermo-Fisher Scientific) and RNA was extracted as recommended by the manufacturer. One-microgram of RNA was reverse transcribed into cDNA using superscript II reverse transcriptase (Life technology) as previously described [18]. Complementary DNA (cDNA) was subsequently loaded into a TaqMan plate (Thermo-Fisher Scientific) and gene expression analysis were performed using SYBR or TaqMan master mix (Thermo Fisher Scientific) and ACTA2 [18], NRF2 [20] or HO1 [20] Sybr primers or predesigned primers and probes for human-COL1A1, COL3A1, FN1, VIM, CDKN1A, CDKN1B, NOX4, CCL2, CXCR4, GAS6, IL1B, IL6, TNF or TNFSF10 (Thermo Fisher Scientific). For mouse lungs, lung tissues were homogenized in Trizol $^{\mathrm{Tm}}$ solution (Thermo Fisher Scientific) using a microsample homogenizer (Pro Scientific). RNA was extracted, and cDNA was generated as described above. Transcriptomic analysis was performed using ACTA2 [18], ENO2 (ENO2F: TCAGGGACTATCCT GTGGT; ENO2R: CATTGGCTGTGAACTTGGA), GLRA1 (GALR1 F: CCATGAGATCACCACAGAC; GALR1 R: GTCAGGGTGATTCTGATGC) or NOX4 (Nox4 F: CTCAGTCTTTGACCCTCGG; Nox4 R: GGAGAGCCAGATGAACAGG) SYBR primers or predesigned primers and probes for human-COL17A1, COL3A1, VIM, CDKN1A and CHGA (Thermo Fisher Scientific). Quantitative PCR analysis was performed using a Viia7 thermocycler (Thermo Fisher Scientific) and the data were analyzed using Data Assist software version 3.01 (Thermo Fisher Scientific).

\section{Soluble collagen 1, IL-8, IL-1ß and in cell aSMA and ß- tubulin ELISA analysis}

Five-thousand lung fibroblasts per well were plated into a 96 well plate, stimulated with $10 \mu \mathrm{M} \mathrm{CpG}, 20 \mathrm{ng} / \mathrm{ml}$ TGFß and/or treated with $300 \mathrm{nM}$ BIBF1120 (Boehrin-

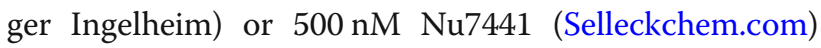
for 24 and $72 \mathrm{~h}$. After stimulation and/or treatment, conditioned supernatants were collected, and the cells were fixed using $4 \%$ paraformaldehyde solution. Collagen-1, IL-8, IL-1ß, $\alpha$ SMA and $\beta$-tubulin proteins were quantified as described under the "Soluble Collagen 1, IL-8, IL$1 ß$ and in cell $\alpha$ SMA and $\beta$-tubulin ELISA analysis" Cells were then analyzed for $\alpha S M A$ protein expression using an in-cell ELISA as previously described [21]. ELISA assays were performed to quantify soluble collagen (as previously described [21]) IL-1ß (R\&D systems) and IL- 8 proteins (R\&D systems) as recommended by the manufacturer.

\section{Flow cytometry}

After Nu7441 treatment, lung fibroblasts were trypsinized for $30-45 \mathrm{~s}$ at room temperature. Trypsin was then inhibited by adding complete medium and the cells were spun down at $400 \mathrm{x} g$ for $5 \mathrm{~min}$. Cells were resuspended in DPBS + 2\% FBS (FACS buffer) and blocked using human TruStain FcX FC receptor blocking solution (Biolegend) for $15 \mathrm{~min}$ on ice. Cells were then stained with anti-SSEA4-APC antibodies (Biolegend) for 15 min at $4{ }^{\circ} \mathrm{C}$, then washed twice with FACS buffer and fixed with $5 \%$ neutral buffered formalin solution. Flow cytometric data were acquired using a MACSQuant analyzer 10 (Miltenyi Biotech) and the data were analyzed using FlowJo version 10.3 (Flowjo, LLC).

\section{Invasive wound healing analysis}

Invasive wound healing assay was performed as previously detailed [21]. Briefly, 96 well ImageLock ${ }^{\text {Tx }}$ plates (Essen BioScience) were pre-coated with Basement membrane extract (BME, Trevigen, $50 \mu \mathrm{g} / \mathrm{mL}$ ) and maintained at room temperature for at least $1 \mathrm{~h}$. Next, BME solution was removed from the plates and fibroblasts were plated $\left(3.5 \times 10^{4} /\right.$ well $)$ and incubated overnight at $37^{\circ} \mathrm{C}$ and $10 \% \mathrm{CO}_{2}$. The wells containing cells were scratched using the WoundMaker ${ }^{\text {tw }}$ (Essen BioScience), washed with PBS and then layered with $4 \mathrm{mg} /$ $\mathrm{ml}$ Matrigel containing vehicle or $500 \mathrm{nM} \mathrm{Nu} 7441$. Cells were monitored using an IncuCyte $\mathrm{ZOOM}$ live cell imager (Essen Biosciences) at $37^{\circ} \mathrm{C}, 10 \% \mathrm{CO}_{2}$ for $150 \mathrm{~h}$. Wound closure was measured using the IncuCyte ZOOM Software (Essen Biosciences) as relative wound density [measurement of the spatial cell density in the wounded area relative to the area outside the wounded area over time]. $0 \%$ represents the wound when there are no cells in the scratched site at $\mathrm{t}=0$ and $100 \%$ represents a wound density where the cell density in the wound is equivalent to the density outside the wound, i.e. $100 \%$ wound healing.

\section{Bioinformatic analysis of publicly available datasets}

Previously analyzed publicly available data sets (GSE103488 [9]) from FACS sorted SSEA4 ${ }^{+}$versus nonsorted SSEA4 ${ }^{-}$cells were re-analyzed as follows: IPF samples utilized in these datasets were divided based on rate of progression, slow progressing IPF (slow-IPF; S161, S109, S170 \& S76A; $n=4)$ or rapid progressing IPF (rapid-IPF; defined as described herein and previous study [18]; S99, S148, S48, S69, S56 \& S180; $n=6$ ), and fold changes were calculated relative to normal cells (NL4, NL7 \& NL16; $n=3$ ) and the data were analyzed using Ingenuity integrated pathway analysis (IPA; QIAGEN Inc., https://www.qiagenbioinformatics.com/ products/ingenuity- pathway-analysis). Stacked bar graphs of enriched ingenuity canonical pathways (depicting the 
percentage of transcripts that were upregulated and down regulated) were set to show all pathways with a minimum $-\log (p$-value) 3.0 or higher. Stacked bar graphs were exported and are depicted in the figures.

\section{Mice}

Eight-Ten-week-old, female, pathogen free NOD CgPrkdc ${ }^{\text {SCID }}$ IL2rg ${ }^{\text {Tm1wil }}$ Szi (NSG) were ordered from Jackson Laboratories. Mice were housed in disposable plastic cages containing Sani-Chip bedding $(n=4-5$ mice per cage) and allowed to acclimate for a minimum of 7 days prior to utilization. To model the loss of DNA-PKcs activity in xenografted IPF cells in NSG mice $(20-25 \mathrm{~g})$, IPF lung explant cells was intravenously administered as previously described [17]. Briefly, mice were physically restrained and $1 \times 10^{6}$ IPF lung explant cell $(0.25 \mathrm{~mL})$ was intravenously injected into the tail vein of each mouse ( $n=4-5$ per group). Thirty-five days after administration, humanized mice were interperitoneally treated with saline or $10 \mathrm{mg} / \mathrm{kg}$ of Nu7441 solution (dissolved at $0.5 \mathrm{mg} / \mathrm{ml}$ in DPBS and sonicated in a water bath sonicator), twice a week for a total of 4 weeks. After a total of 7 weeks (63 days), mice were euthanized by inhalational isoflurane anesthesia overdose, followed by cervical dislocation. Lung tissues were collected for hydroxyproline, protein, and transcriptomic analysis. The mass in the thoracic cavity was micro dissected, fixed and paraffin embedded for histological analysis. Animals were randomly assigned to the experimental groups and experiments were performed once.

\section{Hydroxyproline assay}

Total lung hydroxyproline was quantified and analyzed as previously described [17].

\section{Western blot analysis}

Mouse lung tissues were homogenized in DPBS containing protease inhibitors (Thermo Fisher Scientific) using a microsample homogenizer (Pro Scientific). Total protein content was quantified using a DC Protein assay (Bio-Rad Laboratories, Inc.) and equal amount of protein was prepared and loaded onto an 4-15\% NuPAGE BisTris Protein Gel as recommended by the manufacturer (Thermo-Fisher Scientific). Gels were transferred using an iBlot Dry blotting system onto nitro-cellulose membranes (Thermo-Fisher Scientific) and the transferred samples were blocked for $30 \mathrm{~min}$ at room temperature in $5 \%$ non-fat-dry-milk in tris-buffered saline (TBS). Blots were then washed twice and incubated with antialpha-smooth muscle actin antibodies (Sigma-Aldrich) at $4{ }^{\circ} \mathrm{C}$ overnight. The next day, the blots were washed three times with $0.05 \%$ tween-20 containing TBS solution (TBS-T), incubated with a secondary antibody, washed three times after incubation and developed using a chemiluminescent substrate (Thermo-Fisher Scientific). Images of chemiluminescent bands were acquired using a Bio-Rad Gel documentation system (Bio-Rad Laboratories, Inc.). The blots were then washed in TBS$\mathrm{T}$, blotted with anti-tubulin antibodies (Abcam) and developed in a similar manner. Densitometric analysis were performed using Image Lab Software version 6.0 (Bio-Rad Laboratories, Inc.).

\section{Histologic analysis}

Left lung tissue was collected and processed as previously described [17]. Images were obtained using Zeiss Axio Observer Z1 microscope and the Zeiss Zen 2012 v 1.1.2.0 software (Zeiss) or ScanScope AT System.

\section{Study approval}

All experiments with primary human lung tissues and cell lines derived from these tissues were approved by an IRB at Cedars-Sinai Medical Center and University of Michigan (Approval numbers: Pro00034067 and Pro00044849). Moreover, all patients were informed and written consent to participate was obtained prior to inclusion in the studies. All animal procedures followed the guidelines of the Animal Welfare Act and the Public Health Policy on Humane Care and Use of Laboratory Animals of the United Sates and were approved by the Institutional Animal Care and Use Committee at Cedars-Sinai Medical Center (IACUC005136).

\section{Statistical analysis}

All statistical analyses were performed using GraphPad Prism software version 7 (GraphPad). Data were expressed as means \pm SEM and assessed for significance by One-way ANOVA followed by Tukey's multiple comparisons test or Mann-Whitney two-tailed non-parametric test, as detailed in the figure legends. $P<0.05$ were considered statistically significant.

\section{Results}

\section{Loss of DNA-PKcs protein in IPF lung tissues}

Recently, we have reported that loss of clusterin protein was associated with reduced DNA repair capacity and disrepair in IPF and mouse lung-epithelial cells [9]. Further, a recent report has shown that clusterin protein expression is also down-regulated in IPF lung fibroblasts [22]. In the present study, DNA-PKcs expression was assessed in lung tissues from normal and IPF patients with stable, rapid, and unknown progression of disease by immunohistochemical analysis. Albeit a relatively low number of patient samples were assessed $(n=3$ per group), quantification revealed that DNA-PKcs was significantly decreased in IPF lungs compared to normal lungs (Fig. 1a-e). No significant difference was observed in DNA-PKcs expression between the stable, rapid, and 


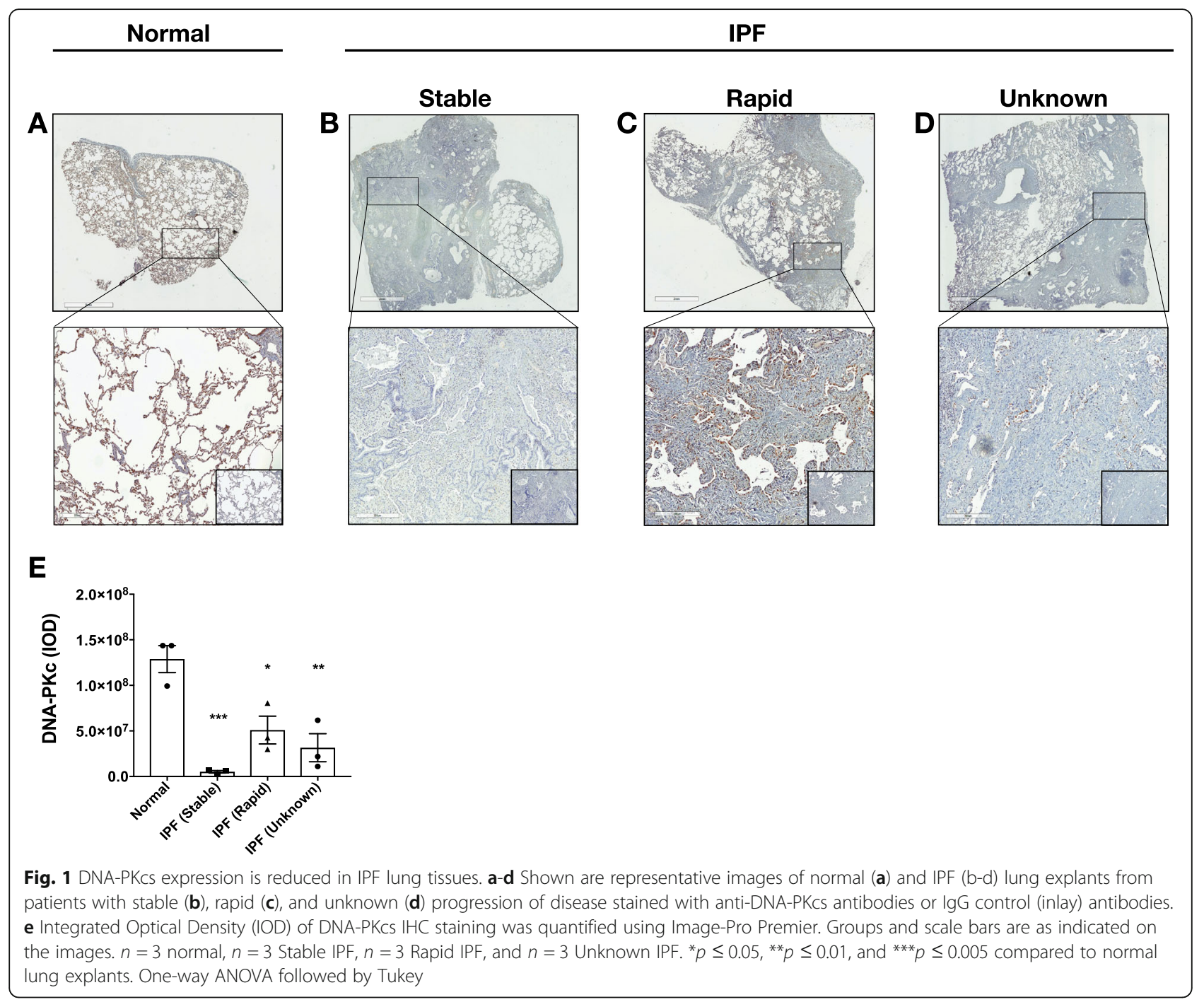

unknown progression IPF groups (Fig. 1a-e), suggesting that DNA-PKcs expression is reduced in IPF compared with normal, regardless of disease progression.

\section{DNA-PKcs is not required for innate DNA sensing of hypomethylated CpG DNA by normal and IPF lung fibroblasts}

Lung fibroblasts differentiate into myofibroblasts in response to hypomethylated CpG DNA (CpG; [18]) stimulation. Further, several reports have suggested that DNA-PKcs is activated in response to CpG stimulation in immune and non-immune cells, where it promotes type I interferon, IL-6, IL-12 and/or IL-10 expression [23-25]. With this background, we next determined whether DNA-PKcs mediated CpG-induced myofibroblast differentiation in primary lung fibroblasts. Immunofluorescence analysis of cells stimulated with $1 \mu \mathrm{M}$ of biotinylated-CpG showed that $\mathrm{CpG}$ was predominantly localized in focal cytosolic and perinuclear regions in normal and IPF lung fibroblasts (Figs. 2b-d, f-h, j-l and 3n-p) after 24h. DNA-PKcs was localized in the nucleus of normal and IPF cells (Fig. 2a, e, i \& m) at this time, but this protein rarely co-localized with biotinylated CpG DNA in normal cells (Fig. 2a-h) and occasionally co-localized with nuclear biotinylated-CpG DNA in IPF cells (Fig. 2i-p, white arrowheads).

To determine the role of this kinase in CpG-induced myofibroblast differentiation, normal and IPF lung fibroblasts were activated with $10 \mu \mathrm{M}$ of CpG and treated with $500 \mathrm{nM}$ of Nu7441 (a specific DNAPKcs small molecule inhibitor [16]) or $300 \mathrm{nM}$ of BIBF-1120 (a multi-receptor tyrosine kinase inhibitor, also known as nintedanib and OFEV) for $24 \mathrm{~h}$. Transcriptomic analysis for myofibroblast markers in these treated cells revealed that $\mathrm{CpG}$ induced an increase of ACTA 2 and COL1A1 transcript expression (Fig. 3a-b) and did not induce any significant changes in COL3A1 and FN1 transcripts (Fig. 3c-d) in normal 


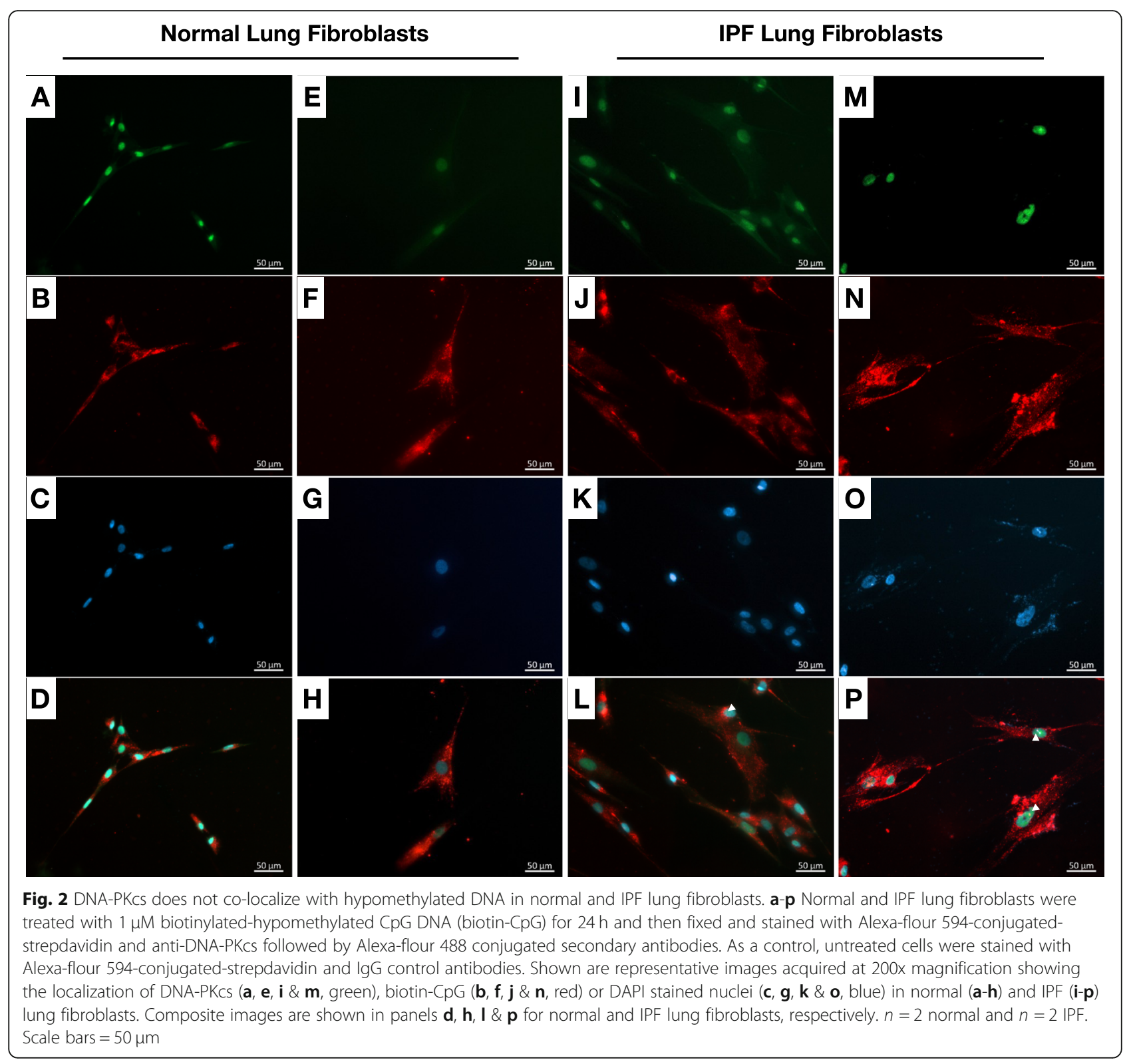

and IPF lung fibroblasts. However, neither Nu7441 or BIBF-1120 treatment significantly reduced CpG-induced ACTA2 or COL1A1 transcript expression in normal or IPF lung fibroblasts (Fig. 3a-b). In separate experiments, cells were stimulated with $10 \mu \mathrm{M}$ CpG or $20 \mathrm{ng} / \mathrm{ml}$ of TGFß1 in the presence or absence of $500 \mathrm{nM} \mathrm{Nu} 7441$ for 24 or $72 \mathrm{~h}$ followed by $\alpha \mathrm{SMA}$, Collagen 1, IL-8 or IL-1ß protein quantification. Seventy-two hours after stimulation, CpG induced a significant increase in secreted collagen 1 protein from one normal lung fibroblast line (Fig. 3f) but did not consistently modulate the secretion of this matrix protein from the other fibroblast lines (Fig. 3e \& g-h, respectively). TGFß1 stimulation significantly increased the concentration of secreted collagen 1 in all four fibroblast lines assessed (Fig. 3e-h). Consistent with the transcriptomic analysis, Nu7441 treatment did not modulate CpG-induced collagen 1 secretion (Fig. 3f) and did not consistently modulate TGFß1-induced collagen 1 secretion, where this inhibitor enhanced TGFß1-induced collagen 1 secretion in one normal fibroblast line (Fig. 3f) and inhibited TGFß1-induced collagen 1 secretion in one IPF fibroblast line (Fig. 3g). Seventy-two hours after treatment, neither CpG nor TGFß1 induced consistent IL-8 protein expression and/ or secretion by normal lung fibroblasts (Fig. 3i), however, TGFß1 promoted IL-8 protein expression and/or secretion by IPF lung fibroblasts, and this effect was enhanced by Nu7441 treatment (Fig. 3j). Further, TGFß1 and, to a lesser extent, CpG, stimulation induced a 


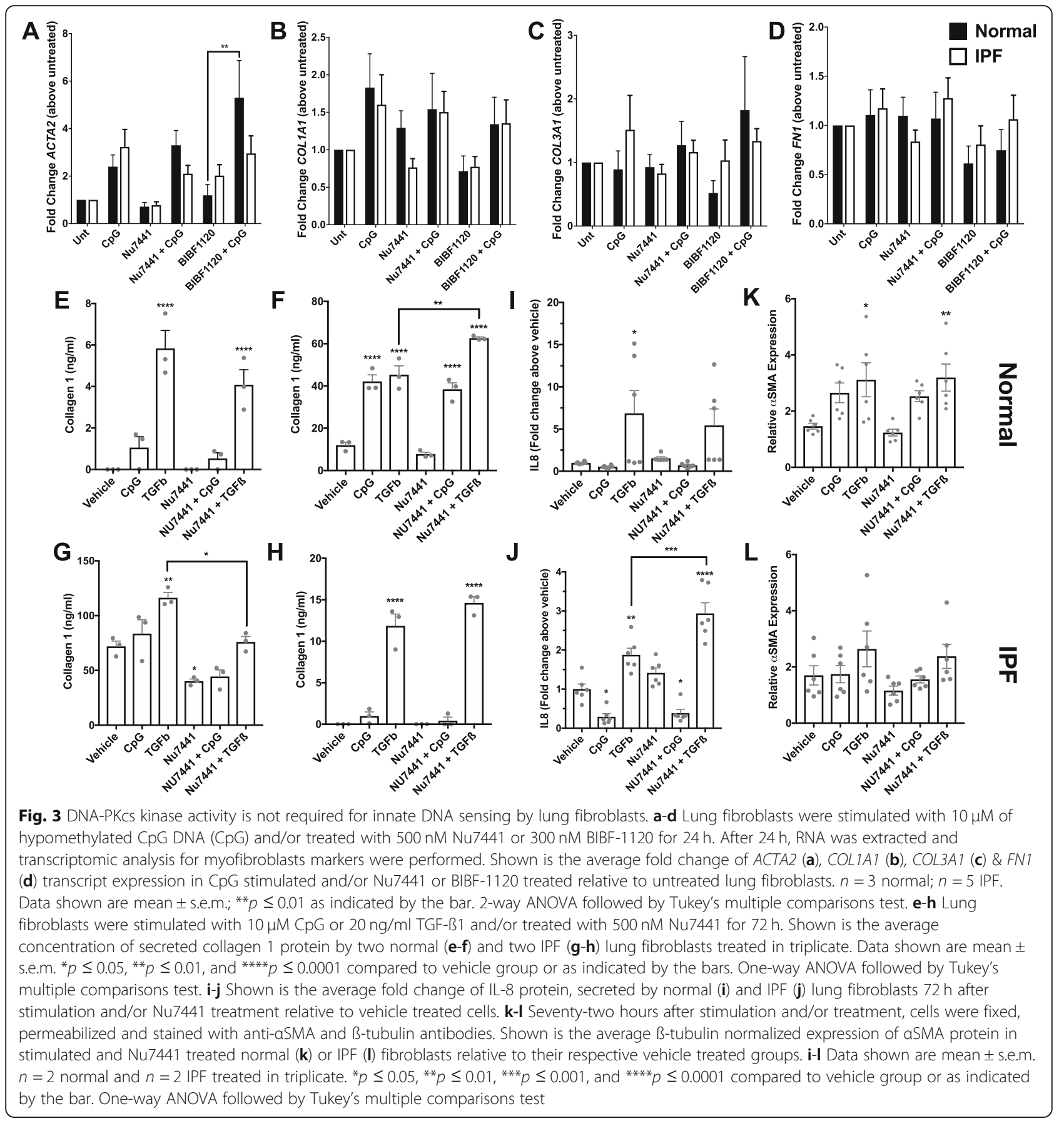

modest and Nu7441- insensitive elevation of $\alpha$ SMA protein expression in normal but not IPF lung fibroblasts (Fig. 3k-1). Finally, neither activators nor Nu7441 treatment induced any consistent changes in IL-1ß protein expression and/or secretion at $24 \mathrm{~h}$ after IPF lung fibroblast treatment and/or stimulation (Additional file 1: Figure S1A-B). Collectively, these results suggest that DNA-PKCs does not regulate CpG-induced lung fibroblasts myofibroblast differentiation but may be involved in senescence.
Chronic inhibition of DNA-PKcs kinase activity leads to an expansion of SSEA4 ${ }^{+}$mesenchymal progenitor cells and the expression of myofibroblast, senescence-associated and inflammatory transcripts by lung fibroblasts

To further explore the persistent inhibition of DNAPKcs in human lung fibroblasts, cells were treated with $500 \mathrm{nM}$ of Nu7441 once every 3 days for a total of 25 days, after which cells were analyzed via flow cytometry and transcriptomic analysis. Untreated cells were utilized as controls. At day 25 after Nu7441 treatment, lung 
fibroblasts were morphologically distinct compared to untreated cells (Fig. 4a-b), most notably cells treated with the inhibitor were more hyperplastic relative to their untreated counterparts. Flow cytometric analysis showed that there was a significant change in the percentage of SSEA4 ${ }^{+}$progenitor cells in Nu7441-treated cultures compared with untreated cultures (Fig. 4c-d). Transcriptomic analysis of Nu7441-treated and untreated fibroblasts showed that this treatment caused a significant increase in the myofibroblast-associated ACTA2 \& VIM (Fig. 4e), the senescence-associated $C D K N 1 A, C D K N 1 B, C D K N 2 A, N O X 4$ (Fig. 4f), and the stress-response and pro-inflammatory transcripts $N R F 2$, CCL2, CXCR4, IL1B and TNFSF10 (Fig. 4g) compared with untreated cells. Surprisingly, Nu7441 treatment significantly reduced COL1A1 transcript relative to untreated fibroblasts (Fig. 4e). We then assessed the modulation of lung fibroblast invasive wound healing by Nu7441. Treatment of lung fibroblasts with $500 \mathrm{nM}$ of $\mathrm{Nu} 7441$ over $150 \mathrm{~h}$ reduced the invasive wound healing in both normal (Additional file 2: Figure S2A-C) and IPF lung fibroblast lines (Additional file 2: Figure S2D-E).
Together, these results demonstrate that inhibition of DNA-PKcs activity enriched for SSEA4 ${ }^{+}$mesenchymal progenitor cells, reduced lung fibroblast invasion, and promoted senescence-associated markers in vitro.

\section{Loss of PRKDC transcript expression and various} components involved in DNA damage response in SSEA4 ${ }^{+}$ mesenchymal progenitor and SSEA4 ${ }^{-}$mesenchymal progeny cells

Next, we assessed the expression of proteins involved in DNA repair in normal and IPF lung fibroblasts and mesenchymal progenitor cells by reanalyzing previously published transcriptomic datasets (GSE103488 [9]) from sorted normal and IPF SSEA4 ${ }^{+}$mesenchymal progenitor cells $[6,26]$ and SSEA $^{-}$fibroblasts based on IPF progression. The IPF datasets were grouped by progression as follows: slow progressing IPF (slow-IPF; S161, S109, S170 \& S76A) versus rapid progressing IPF (rapidIPF; defined in the methods section and as previously described [18]; S99, S148, S48, S69, S56 \& S180). Fold-changes were then calculated for each

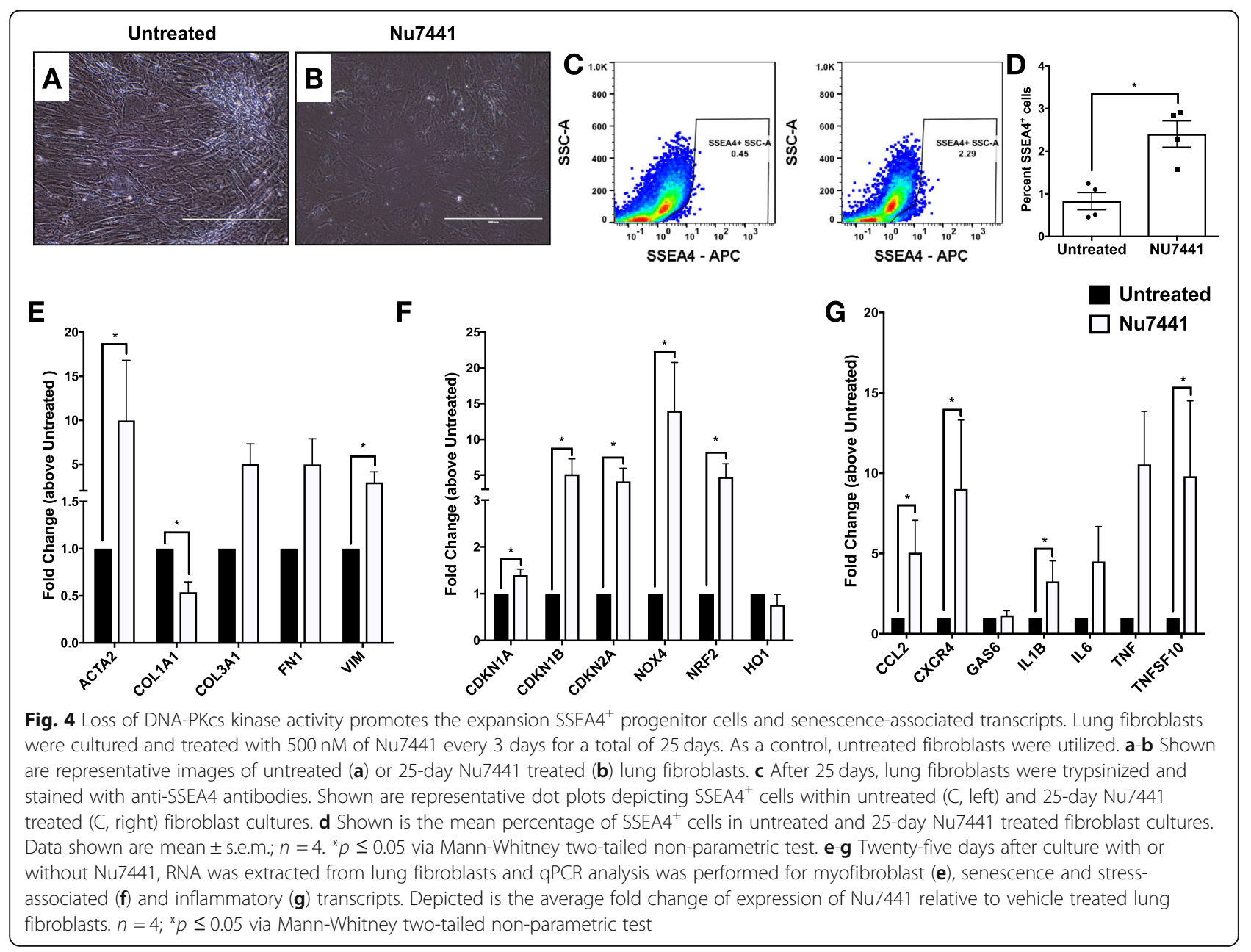


group compared with normal cells and the data were analyzed using Ingenuity Integrated Pathway Analysis (IPA). As summarized in Fig. 5, a loss of transcripts encoding for components of various DNA damage response and repair proteins were observed in both rapid-IPF SSEA4 ${ }^{+}$(Fig. 5a) and SSEA4 ${ }^{-}$cells (i.e. progeny) (Fig. 5b), including role of BRCA1 in DNA damage response, ATM signaling, mismatch repair in eukaryotes, BER pathway and Cell cycle: G2/M DNA damage checkpoint regulation pathways compared with the normal mesenchymal progenitors and progeny. However, these pathways were not present following a comparison of SSEA4 ${ }^{+}$and SSEA4 ${ }^{-}$cells from slow progressing IPF patients with normal mesenchymal cell types (Additional file 3: Figure S3A-B). Because of the loss of various DNA repair pathways in progenitor and mesenchymal cells, we next assessed the expression of PRKDC (encoding for DNA-PKcs), which is required for DNA damage signaling, double strand break repair, telomere maintenance and resistance to oxidative stress $[11,12,27$, 28 ] in rapid- and slow-IPF SSEA $4^{+}$progenitors and SSEA4 $4^{-}$fibroblasts. Mining of transcriptomic datasets showed that there was a loss PRKDC transcript in cells derived from rapid-IPF fibroblast cultures (Fig. 5c-d). Together, these results suggest that cultured SSEA4 ${ }^{+}$mesenchymal progenitor and SSEA4 ${ }^{-}$ mesenchymal progeny cells from progressive IPF patients were characterized by a loss of PRKDC transcript expression and various components involved in DNA damage response and/or DNA damage repair pathways.

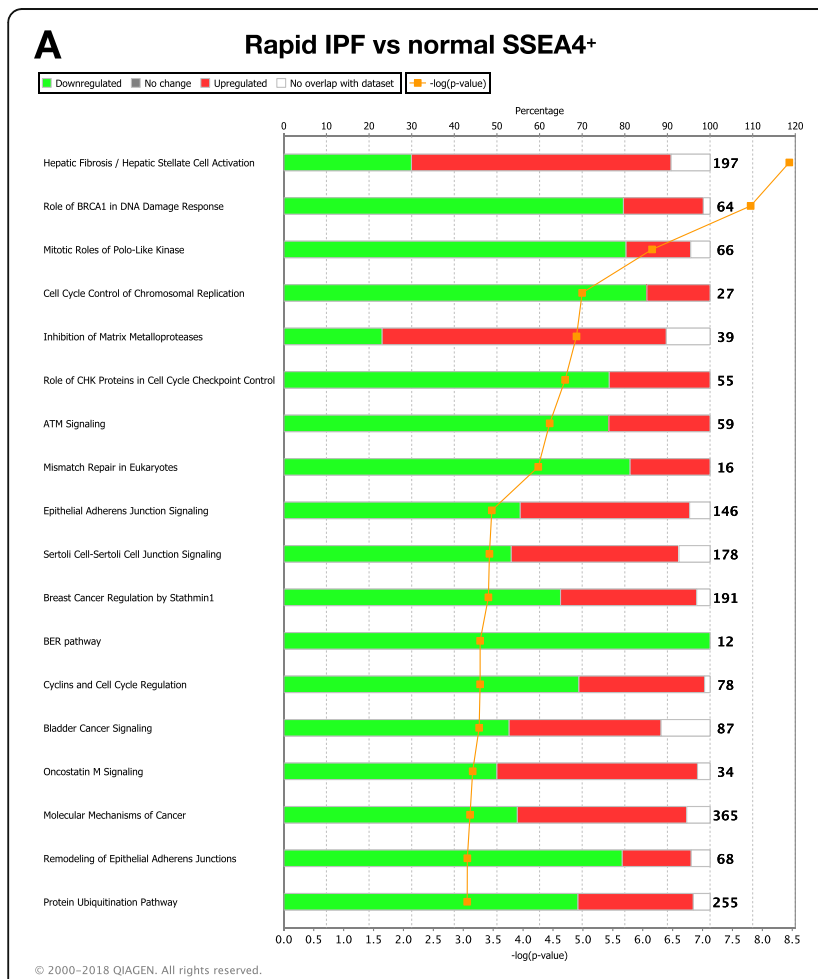

\section{B} Rapid IPF vs normal SSEA4

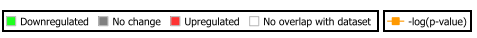

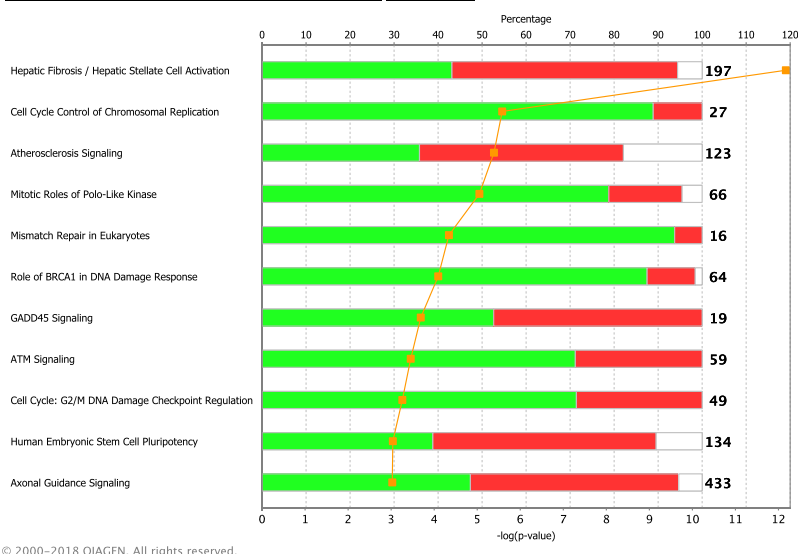

2000-2018 0iacrN All rights reserved.
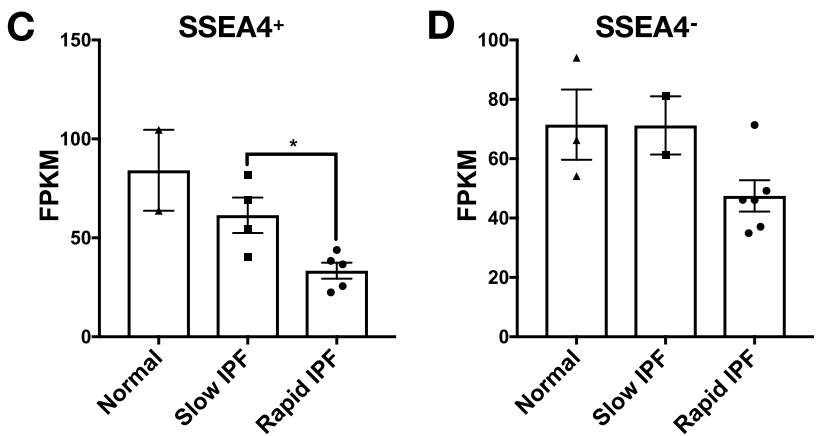

Fig. 5 LosS of PRKDC transcript and DNA damage response components in SSEA4 ${ }^{+}$and SSEA4 ${ }^{-}$IPF fibroblasts. SSEA4 ${ }^{+}$cells were sorted from normal and IPF lung fibroblast cultures. RNA was extracted from the sorted cells SSEA4 ${ }^{+}$and non-sorted SSEA4 $4^{-}$cells and subject to RNA sequencing analysis as previously described (GSE103488 [9]). a-b Shown are Ingenuity canonical pathway analysis of Rapid-IPF versus normal SSEA4 ${ }^{+}$cells (a) and Rapid-IPF versus normal SSEA4 ${ }^{-}$cells (b). Ingenuity was set to consider transcripts with an FPKM value $\geq 0.2$ and a fold change $\geq 1.5 \& \leq-1.5$ (a) and FPKM value $\geq 1$ and a fold change $\geq 1.5 \& \leq-1.5$ (b). Percentage depicts the proportion of transcripts from the transcriptomic analysis that are annotated in the Ingenuity canonical pathway. The percentage of transcripts that are downregulated or upregulated in each canonical pathway are depicted in green or red, respectively. c-d Shown are the mean FPKM counts for PRKDC in normal, slow-IPF and rapid-IPF SSEA4 ${ }^{+}$progenitors (a) and SSEA4 ${ }^{-}$fibroblasts (b). Data shown are mean \pm s.e.m.; $n=2-5 / g r o u p .{ }^{*} p \leq 0.05$ via MannWhitney two-tailed non-parametric test 
CgA protein is highly expressed by SSEA4 ${ }^{+}$mesenchymal progenitor cells and in IPF lung tissues

Given the expansion of SSEA4 ${ }^{+}$cells in fibroblast cultures that were treated chronically with Nu7441, further characterization of these cells was performed. Several reports have suggested that SSEA4 ${ }^{+}$cells are mesenchymal progenitor cells $[6,26]$ and we have recently observed that these cells are also enriched with basal-epithelial cell transcripts [9]. Mining of transcriptomic datasets (GSE103488 [9]) for additional airway epithelial cell lineage markers showed that these cells expressed various markers of neuroendocrine cells, including ENO2, CHGA, SYP and GLRA1 (Fig. 6a). Further, these markers tended to be significantly enriched in SSEA4 ${ }^{+}$cells from slow-IPF or normal lung fibroblast cultures (Fig. 6a). Consistently, SSEA4 ${ }^{+}$cells from normal and IPF lungs abundantly expressed $\mathrm{CgA}$ protein as determined by intracellular flow cytometric analysis (Fig. 6b-c). Rare CgA or SSEA4 immuno-positive cells were detected in normal lung tissues (Fig. 6d, top) but there was an abundance of cells that expressed both CgA and SSEA4 proteins in IPF lungs (Fig. 6d, middle and bottom, Additional file 4: Figure S4). Further, IHC analysis for CgA protein in normal and IPF lung tissues showed that this protein is rarely detected in normal lungs (Fig. 6e) but CgA-positive cells were detected in slow-IPF, rapid-IPF lung biopsies (Fig. 6f-g), and most abundant in end stage lung-explants (Fig. 6h-i). Thus, these results demonstrate that SSEA4 ${ }^{+}$mesenchymal progenitor cells express the neuroendocrine marker, $\mathrm{CgA}$ and that there appears to be an expansion of these cells as IPF progresses.

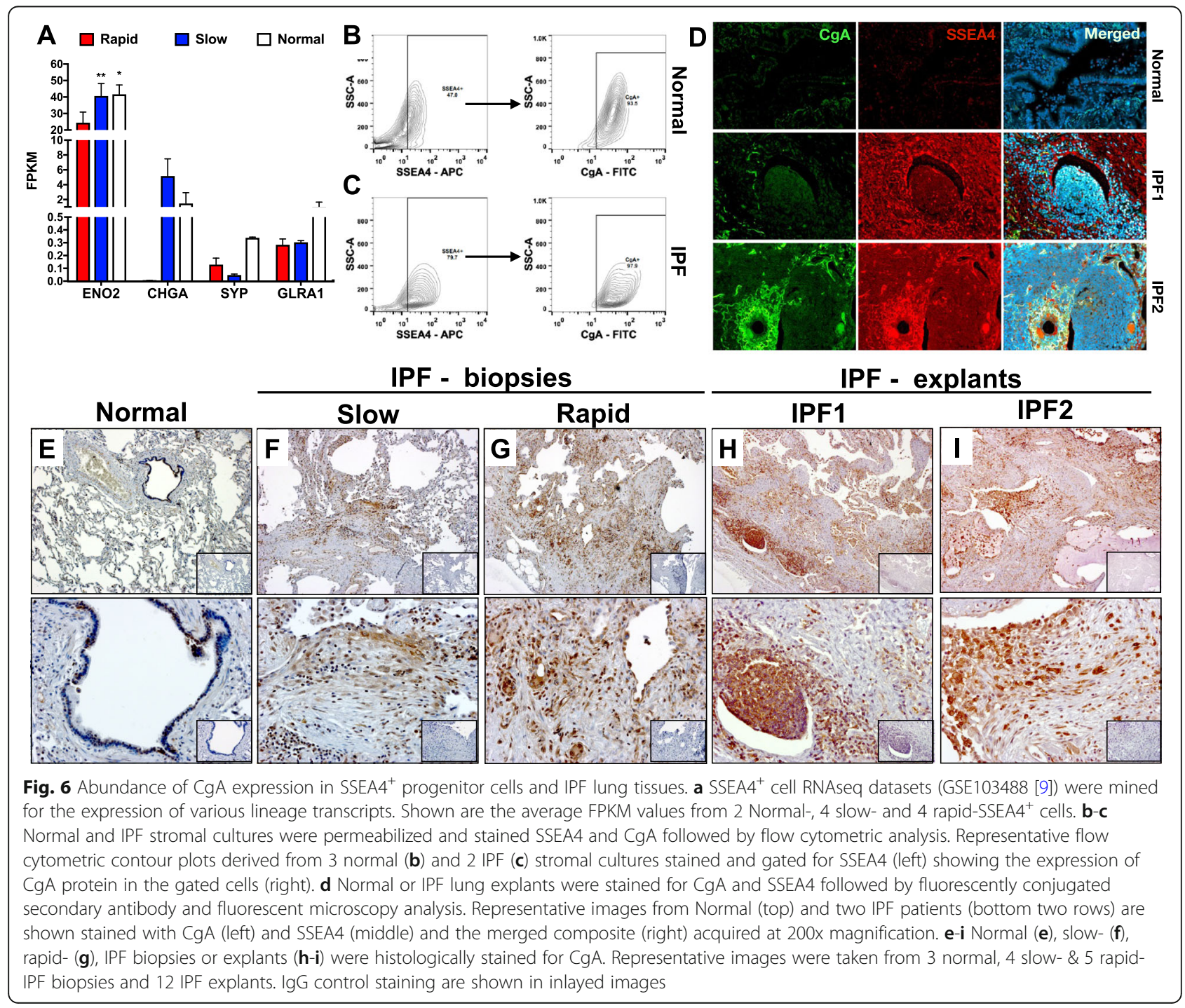


Inhibition of DNA-PKcs activity promoted the expansion of SSEA4 ${ }^{+} \mathrm{CgA}^{+}$cells in humanized NSG mice

Our final set of experiments addressed the effects of DNA-PKcs on lung fibrosis in vivo. Recently, we developed a novel humanized NSG model of IPF in which immune and non-immune cells derived from explanted IPF tissue are intravenously administered into NSG mice and induce lung remodeling that is apparent by day 35 after introduction [17]. To study the role of DNA-PKcs in humanized NSG mice, mice were intravenously administered with IPF cells and starting at day 35 after cellular administration, mice were treated interperitoneally with $10 \mathrm{mg} / \mathrm{kg}$ of Nu7441 or saline, twice a week for 4 weeks (Fig. 7a). As aforementioned, Nu7441 is a potent and highly selective inhibitor of DNA-PK. In this study, it was used to target injected IPF cells and mimic the loss of DNA-PK observed in IPF. Nu7441 treatment did not modulate hydroxyproline levels in humanized mice relative to the saline-treated groups (Fig. 7b), aSMA protein levels (Fig. 7c), lung remodeling (Fig. 7d) or transcripts encoding for ACTA2, COL17A1, COL3A1, VIM, CDKN1A, CDKN1B, CHGA, ENO2, GLRA1 and NOX4 (Fig. 7e) ( $n=4-5$ mice per group). However, in $20 \%$ of the humanized NSG mice treated with $\mathrm{Nu} 7441$, there was a mass in the thoracic cavity (Fig. 7f) $(n=1)$. IHC analysis on tissue extracted from this mass showed that cells within this mass highly expressed human-S100A4 (Fig. 7g), SSEA4 (Fig. 7h), CgA (Fig. 7i), CCR10 (Fig. 7j) and Ki-67 (Fig. 7k) proteins. Collectively, these results suggest that DNA-PKcs may protect

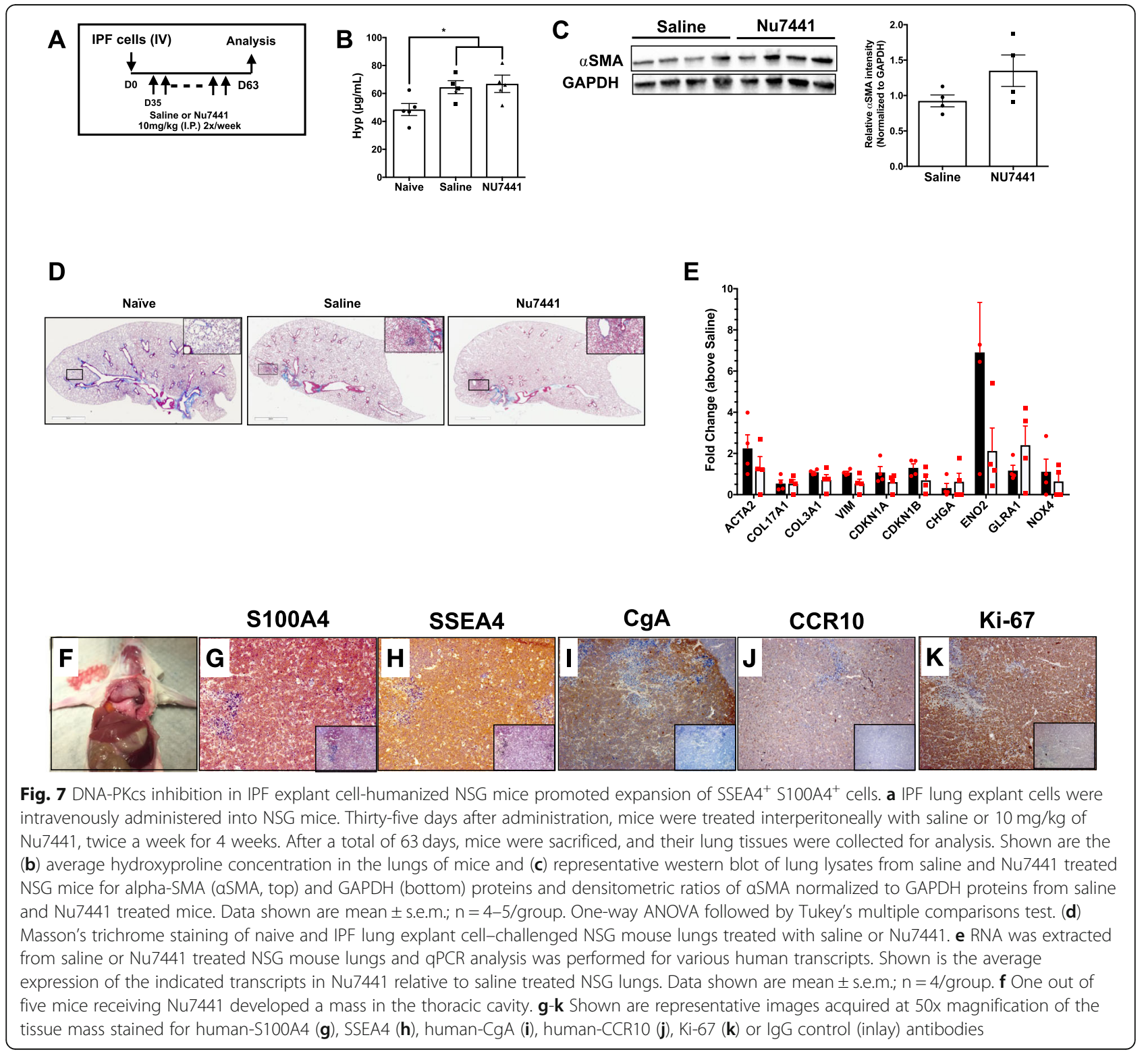


against extracellular matrix deposition and the expansion of mesenchymal progenitor cells in vivo.

\section{Discussion}

IPF is a lethal fibrotic lung disease, characterized by excessive ECM deposition leading to the loss of the lung's architecture and function. This disease is characterized by shortened telomeres in structural cells [3, 29-31], senescence of epithelial progenitor and stromal cells [30, 32-39], microsatellite instability $[40,41]$ and an increased incidence of lung cancer $[42,43]$. However, mechanisms accounting for these features in IPF remain elusive. Given the previously reported role of DNA-PKcs in innate DNA sensing [25, 44], genomic stability, telomere capping and maintenance, cell replication and DNA-damage repair [11, 12], we further assessed both the expression and function of this protein in IPF. In this report, we observed the reduced expression of DNA-PK in the lungs of IPF patients and mesenchymal progenitor cells $\left(\mathrm{SSEA} 4^{+}\right.$cells) and fibroblasts (SSEA4 ${ }^{-}$cells) from IPF patients. Moreover, targeting DNA-PK in vitro revealed the important role of this kinase in regulating senescence in these cell types.

Because DNA-PKcs has been explored in innate DNA sensing [11, 12], studies were first performed to assess the role of this kinase in CpG-mediated fibroblast to myofibroblast differentiation. Immunofluorescence analysis suggested that DNA-PKcs primarily localized in the nucleus of both normal and IPF lung fibroblasts. Twenty-four hours after CpG treatment, this kinase localized in endosomal and peri-nuclear regions with rare localization in the nucleus. Further, we rarely detected colocalization of CpG-DNA and DNA-PKcs, suggesting that this kinase may not act as an innate DNA sensor in lung fibroblasts. Indeed, inhibiting this kinase failed to modulate CpG-induced Collagen 1, $\alpha$-SMA and IL-1 $\beta$ protein expression in lung fibroblasts. Consistently, the expression of DNA-PKcs transcripts were significantly reduced in SSEA4 ${ }^{+}$mesenchymal progenitor cells and fibroblasts derived from lung tissues of rapidly progressing IPF patients, where we most consistently observe robust CpG mediated myofibroblast differentiation [18]. These results suggest that IPF lung fibroblasts may not utilize DNA-PKcs as an innate DNA sensor.

DNA-PKcs acts as a scaffold and a kinase, where the loss of its kinase activity leads to telomeric aberrations, and radiation sensitization due to reduced NHEJ DNA repair [45-47]. To model the loss of DNA-PKcs in IPF, we chronically treated human lung fibroblast cultures with a highly specific small molecule kinase inhibitor, NU7441 [16]. Chronic treatment of lung fibroblasts with Nu7441 accelerated fibroblast senescence in vitro as evidenced by the increased expression of various senescence markers in these cells. Given the role of DNA$\mathrm{PKcs}$ in DNA repair and checkpoint signaling during replication stress $[48,49]$, this senescence effect may be due to increased replication stress in the treated cells. This finding is consistent with other studies showing the induction of senescence because of replication stress [50], and suggests that the loss of this kinase may contribute to the abundance of senescent cells in IPF lungs [30, 32-38]. Surprisingly, in in vivo studies, DNA-PKcs inhibition via Nu7441 treatment did not change the expression of senescence markers in the lung tissues. However, these studies were performed in mice lacking DNA-PKcs kinase activity (due to a mutation in the gene encoding for this protein) and thus the lack of any observed effects may be due to the dilution of DNA-PKcs expressing human cells in the mouse lungs. Interestingly, $20 \%$ of humanized NSG mice treated with this inhibitor showed a marked expansion in SSEA4 ${ }^{+}$mesenchymal progenitor cells, which were also positive for CgA, S100A4 [26], and CCR10. Further, most of the cells expressed high levels of Ki-67 protein, suggesting a high proliferative index. Given the role of DNA-PKcs in replication stress and its role in preventing telomeric fusions $[11,12]$, it is possible that targeting this protein in vivo promoted genomic instability and subsequently increased the proliferation of these progenitor cells. However, further studies are required to fully address this possibility since this was observed in only one mouse in the current study.

Since SSEA4 ${ }^{+}$cells were expanded in Nu7441-treated humanized NSG mice, we undertook additional analyses of these cells to determine what other markers these progenitor cells expressed $[6,26]$. Surprisingly, this analysis indicated these cells expressed multiple neuroendocrine markers. Indeed, pulmonary neuroendocrine cells were reported to be among the first specialized cell type to appear during lung development [51]. Further, celltracing studies have indicated that neuroendocrine cells can give rise to various epithelial cells, including club cells, ciliated cells in response to naphthalene-induced injury [52], which is consistent with the co-expression of various epithelial and neuroendocrine markers in cultured SSEA $4^{+}$cells. Nevertheless, in addition to epithelial and neuroendocrine markers, SSEA4 ${ }^{+}$cells also expressed stromal markers suggesting that these cells may also give rise to stromal cells. Interestingly, the SSEA4 ${ }^{+}$mesenchymal progenitor cells detected in humanized SCID mice highly expressed the neuroendocrine marker, $\mathrm{CgA}$, and there was an expansion of $\mathrm{CgA}$ expressing cells in IPF lungs. This finding is consistent with a previous report [53], and suggests that there may be aberrant neuroendocrine cells in IPF, and DNA-PKcs regulates the differentiation of SSEA4 ${ }^{+}$mesenchymal progenitor cells. Thus, the loss of DNA-PKcs in IPF might be associated with the emergence of a diverse array of cell types from SSEA4 ${ }^{+}$progenitor cells 
including those with epithelial cell, neuroendocrine, and/or mesenchymal cell properties.

\section{Conclusions}

In summary, these results demonstrate that loss of DNA-PKcs promotes the expansion of SSEA4 ${ }^{+}$mesenchymal progenitor cells and the senescence of fibroblasts in IPF. Additional studies are warranted to further explore the DNA-PKcs-dependent mechanisms leading to the proliferation of pathologic SSEA4 ${ }^{+}$ mesenchymal progenitor cells and the senescence of differentiated mesenchymal cells, and whether these events are modulated by FDA-approved IPF therapeutics including Ofev and Esbriet or other emerging IPF therapeutics.

\section{Additional files}

Additional file 1: Figure S1. Inhibition of DNA-PKCs kinase activity does not modulate CPG-mediated IL 1 B secretion by IPF lung fibroblasts. Lung fibroblasts were stimulated with $10 \mu \mathrm{M} \mathrm{CpG}$ or $20 \mathrm{ng} / \mathrm{ml}$ TGF-B1 and/or treated with $500 \mathrm{nM}$ Nu7441 for $24 \mathrm{~h}$. (A-B) Shown is the average concentration of IL1ß secreted from two senescent IPF lung fibroblasts lines after stimulation and/or Nu7441 treatment in triplicate. (PDF 42 kb)

Additional file 2: Figure S2. Inhibition of DNA-PKcs ameliorated lung fibroblast invasive wound healing. Lung fibroblasts were then plated into 96 well plates, scratched using a WoundMaker ${ }^{\mathrm{TM}}$ and then layered with 4 $\mathrm{mg} / \mathrm{ml}$ Matrigel containing vehicle or $500 \mathrm{nM}$ Nu7441. Lung fibroblast invasive wound healing was monitored using an Incucyte Zoom live cell imager. Depicted is a kinetic read-out of wound closure (relative to the initial wound) over $150 \mathrm{~h}$ of three normal (A-C) and two IPF (D-E) lung fibroblasts treated in triplicate. (PDF $239 \mathrm{~kb}$ )

Additional file 3: Figure S3. Ingenuity canonical pathways enriched in Slow-IPF SSEA4 ${ }^{+}$and SSEA4 ${ }^{-}$cells compared to normal cells. SSEA4 ${ }^{+}$cells were sorted from normal and IPF lung fibroblast cultures. RNA was extracted from the sorted cells SSEA4 $4^{+}$and non-sorted SSEA4 $4^{-}$cells and subject to RNA sequencing analysis as previously described (GSE103488). (A-B) Shown are Ingenuity canonical pathway analysis of Slow-IPF versus normal SSEA4 $4^{+}$cells (A) and Slow-IPF versus normal SSEA4 ${ }^{-}$cells (B). Ingenuity was set to consider transcripts with an FPKM value $\geq 0.2$ and a fold change $\geq 1.5 \& \leq-1.5$ (A) and FPKM value $\geq 1$ and a fold change $\geq 1.5 \& \leq-1.5$ (B). Percentage depicts the proportion of transcripts from the transcriptomic analysis that are annotated in the Ingenuity canonical pathway. The percentage of transcripts that are downregulated or upregulated in each canonical pathway are depicted in green or red, respectively. (PDF $793 \mathrm{~kb}$ )

Additional file 4: Figure S4. Immunofluorescence IgG control staining of IPF lung tissues. Normal or IPF lung explants were stained IgG antibodies followed by fluorescently conjugated secondary antibodies and microscopy analysis. Representative images from two IPF patients are shown stained with lgG + Alexa Flour 488 conjugated secondary antibody (left), lgG + Alexa Flour 594 conjugated secondary antibody (middle) and the merged composite (right) acquired at 200x magnification. (PDF $405 \mathrm{~kb}$ )

\section{Abbreviations}

CpG: Hypomethylated CpG DNA; DNA-Pkcs: DNA-dependent protein kinase; ILD: Interstitial lung diseases; IPF: Idiopathic pulmonary fibrosis; SSEA: Stagespecific embryonic antigen

\section{Acknowledgements}

N/A

\section{Authors' contributions}

Conception and design: $\mathrm{DMH}, \mathrm{MSH}, \mathrm{MSE}, \mathrm{CMH}$; Acquisition of data: $\mathrm{DMH}$ MSH, MSE, ALC, ICJ, HJ, RC, IP, FW, CMH; Analysis and interpretation of data: DMH, MSH, MSE, ALC, ICJ, HJ, RC, IP, FW, CMH; Drafting the manuscript and intellectual content: DMH, MSH, MSE, CMH. ${ }^{*} \mathrm{DMH}$ and MSH contributed equally to this manuscript. All authors have read and approved the manuscript.

\section{Funding}

The National Institute of Health (R01HL123899; CMH) and (T32-HL007517-30; DH). Cedars-Sinai Medical Center (DH; MSH, MSE; ALC; ICJ, HJ). Both funding bodies supported all the studies conducted in this manuscript, as well as the authors specified above. The funding bodies had no role in the design of the study and collection, analysis, and interpretation of data and in writing the manuscript.

\section{Availability of data and materials}

Data and materials will be available for public upon request to the corresponding authors MSH (miriam.hohmann@cshs.org) or CMH (cory. hogaboam@cshs.org).

\section{Ethics approval and consent to participate}

Institutional review boards at Cedars-Sinai Medical Center and the University of Michigan approved all experiments with primary human lung tissues and cell lines derived from these tissues. All patients were informed and written consent to participate was obtained prior to inclusion in the studies (Approval number: Pro00034067 and Pro 00044849). All animal studies followed the guidelines of the Animal Welfare Act and the Public Health Policy on $\mathrm{Hu}-$ mane Care and Use of Laboratory Animals of the United Sates and were approved by the Institutional Animal Care and Use Committee at Cedars-Sinai Medical Center (IACUC005136).

\section{Consent for publication \\ N/A}

\section{Competing interests}

Authors declare that they have no competing interests.

\section{Author details}

'Department of Medicine, Cedars-Sinai Medical Center, Women's Guild Lung Institute, 127 S San Vicente Blvd., AHSP A9315, Los Angeles, CA 90048, USA. ${ }^{2}$ Laboratory of Dynamic Imaging, Mechanical and Aerospace Engineering, Monash University, Clayton, VIC 3800, Australia.

Received: 29 November 2018 Accepted: 19 August 2019

Published online: 29 August 2019

\section{References}

1. Antoniou KM, Margaritopoulos GA, Tomassetti S, Bonella F, Costabel U, Poletti V. Interstitial lung disease. Eur Respir Rev. 2014;23(131):40-54.

2. Ley B, Collard HR, King TE Jr. Clinical course and prediction of survival in idiopathic pulmonary fibrosis. Am J Respir Crit Care Med. 2011;183(4):431-40.

3. Chilosi M, Doglioni C, Murer B, Poletti V. Epithelial stem cell exhaustion in the pathogenesis of idiopathic pulmonary fibrosis. Sarcoidosis Vasc Diffuse Lung Dis. 2010;27(1):7-18.

4. Wolters PJ, Collard HR, Jones KD. Pathogenesis of idiopathic pulmonary fibrosis. Annu Rev Pathol. 2014;9:157-79.

5. Camelo A, Dunmore R, Sleeman MA, Clarke DL. The epithelium in idiopathic pulmonary fibrosis: breaking the barrier. Front Pharmacol. 2014;4:173.

6. Xia H, Bodempudi V, Benyumov A, Hergert P, Tank D, Herrera J, Braziunas J, Larsson O, Parker M, Rossi D, et al. Identification of a cell-of-origin for fibroblasts comprising the fibrotic reticulum in idiopathic pulmonary fibrosis. Am J Pathol. 2014;184(5):1369-83.

7. Reya T, Morrison SJ, Clarke MF, Weissman IL. Stem cells, cancer, and cancer stem cells. Nature. 2001;414(6859):105-11.

8. Kumar V, Fleming T, Terjung S, Gorzelanny C, Gebhardt C, Agrawal R, Mall MA, Ranzinger J, Zeier M, Madhusudhan T, et al. Homeostatic nuclear RAGEATM interaction is essential for efficient DNA repair. Nucleic Acids Res. 2017; 45(18):10595-613. 
9. Habiel DM, Camelo A, Espindola M, Burwell T, Hanna R, Miranda E, Carruthers A, Bell M, Coelho AL, Liu H, et al. Divergent roles for Clusterin in lung injury and repair. Sci Rep. 2017;7:15444.

10. Zhou Y, Lee JH, Jiang W, Crowe JL, Zha S, Paull TT. Regulation of the DNA damage response by DNA-PKcs inhibitory phosphorylation of ATM. Mol Cell. 2017:65(1):91-104.

11. Davis AJ, Chen BP, Chen DJ. DNA-PK: a dynamic enzyme in a versatile DSB repair pathway. DNA Repair (Amst). 2014;17:21-9.

12. Jette N, Lees-Miller SP. The DNA-dependent protein kinase: a multifunctional protein kinase with roles in DNA double strand break repair and mitosis. Prog Biophys Mol Biol. 2015;117(2-3):194-205.

13. Peters NE, Ferguson BJ, Mazzon M, Fahy AS, Krysztofinska E, Arribas-Bosacoma R, Pearl LH, Ren H, Smith GL. A mechanism for the inhibition of DNA-PKmediated DNA sensing by a virus. PLoS Pathog. 2013;9(10):e1003649.

14. Hill R, Madureira PA, Waisman DM, Lee PW. DNA-PKCS binding to p53 on the p21WAF1/CIP1 promoter blocks transcription resulting in cell death. Oncotarget. 2011;2(12):1094-108.

15. Li YH, Wang X, Pan Y, Lee DH, Chowdhury D, Kimmelman AC. Inhibition of non-homologous end joining repair impairs pancreatic cancer growth and enhances radiation response. PLoS One. 2012;7(6):e39588.

16. Leahy JJ, Golding BT, Griffin RJ, Hardcastle IR, Richardson C, Rigoreau L, Smith GC. Identification of a highly potent and selective DNA-dependent protein kinase (DNA-PK) inhibitor (NU7441) by screening of chromenone libraries. Bioorg Med Chem Lett. 2004;14(24):6083-7.

17. Habiel DM, Espindola MS, Coelho AL, Hogaboam CM. Modeling idiopathic pulmonary fibrosis in humanized severe combined Immunodeficient mice. Am J Pathol. 2018;188(4):891-903.

18. Trujillo G, Meneghin A, Flaherty KR, Sholl LM, Myers JL, Kazerooni EA, Gross $\mathrm{BH}$, Oak SR, Coelho AL, Evanoff H, et al. TLR9 differentiates rapidly from slowly progressing forms of idiopathic pulmonary fibrosis. Sci Transl Med. 2010;2(57):57ra82.

19. Flaherty KR, King TE Jr, Raghu G, Lynch JP 3rd, Colby TV, Travis WD, Gross $\mathrm{BH}$, Kazerooni EA, Toews GB, Long Q, et al. Idiopathic interstitial pneumonia: what is the effect of a multidisciplinary approach to diagnosis? Am J Respir Crit Care Med. 2004;170(8):904-10.

20. Habiel DM, Krepostman N, Lilly M, Cavassani K, Coelho AL, Shibata T, Elenitoba-Johnson K, Hogaboam CM. Senescent stromal cell-induced divergence and therapeutic resistance in T cell acute lymphoblastic leukemia/lymphoma. Oncotarget. 2016;7(50):83514-29.

21. Espindola MS, Habiel DM, Narayanan R, Jones I, Coelho AL, Murray LA, Jiang D, Noble PW, Hogaboam CM. Targeting of TAM receptors ameliorates fibrotic mechanisms in idiopathic pulmonary fibrosis. Am J Respir Crit Care Med. 2018;197:1443.

22. Peix L, Evans IC, Pearce DR, Simpson JK, Maher TM, McAnulty RJ. Diverse functions of clusterin promote and protect against the development of pulmonary fibrosis. Sci Rep. 2018;8(1):1906.

23. Hazeki K, Kametani Y, Murakami H, Uehara M, Ishikawa Y, Nigorikawa K Takasuga S, Sasaki T, Seya T, Matsumoto M, et al. Phosphoinositide 3kinasegamma controls the intracellular localization of CpG to limit DNA-PKcsdependent IL-10 production in macrophages. PLoS One. 2011;6(10):e26836.

24. Ma C, Muranyi M, Chu CH, Zhang J, Chu WM. Involvement of DNA-PKcs in the $I \mathrm{~L}-6$ and $\mathrm{IL}-12$ response to $\mathrm{CPG}-\mathrm{ODN}$ is mediated by its interaction with TRAF6 in dendritic cells. PLoS One. 2013:8(3):e58072.

25. Ma C, Spies NP, Gong T, Jones CX, Chu WM. Involvement of DNA-PKcs in the type I IFN response to CpG-ODNs in conventional dendritic cells in TLR9-dependent or -independent manners. PLoS One. 2015;10(3):e0121371.

26. Xia H, Gilbertsen A, Herrera J, Racila E, Smith K, Peterson M, Griffin T, Benyumov A, Yang L, Bitterman PB, et al. Calcium-binding protein S100A4 confers mesenchymal progenitor cell fibrogenicity in idiopathic pulmonary fibrosis. J Clin Invest. 2017;127(7):2586-97.

27. Li M, Lin YF, Palchik GA, Matsunaga S, Wang D, Chen BP. The catalytic subunit of DNA-dependent protein kinase is required for cellular resistance to oxidative stress independent of DNA double-strand break repair. Free Radic Biol Med. 2014;76:278-85.

28. Peddi P, Loftin CW, Dickey JS, Hair JM, Burns KJ, Aziz K, Francisco DC, Panayiotidis MI, Sedelnikova OA, Bonner WM, et al. DNA-PKcs deficiency leads to persistence of oxidatively induced clustered DNA lesions in human tumor cells. Free Radic Biol Med. 2010;48(10):1435-43.

29. Alder JK, Chen JJ, Lancaster L, Danoff S, Su SC, Cogan JD, Vulto I, Xie M, Qi $X$, Tuder RM, et al. Short telomeres are a risk factor for idiopathic pulmonary fibrosis. Proc Natl Acad Sci U S A. 2008;105(35):13051-6.
30. Liu T, Ullenbruch M, Young Choi Y, Yu H, Ding L, Xaubet A, Pereda J, Feghali-Bostwick CA, Bitterman PB, Henke CA, et al. Telomerase and telomere length in pulmonary fibrosis. Am J Respir Cell Mol Biol. 2013; 49(2):260-8.

31. Snetselaar R, van Moorsel CHM, Kazemier KM, van der Vis JJ, Zanen P, van Oosterhout MFM, Grutters JC. Telomere length in interstitial lung diseases. Chest. 2015;148(4):1011-8.

32. Chilosi M, Carloni A, Rossi A, Poletti V. Premature lung aging and cellular senescence in the pathogenesis of idiopathic pulmonary fibrosis and COPD/emphysema. Transl Res. 2013;162(3):156-73.

33. Hecker L, Logsdon NJ, Kurundkar D, Kurundkar A, Bernard K, Hock T, Meldrum E, Sanders YY, Thannickal VJ. Reversal of persistent fibrosis in aging by targeting Nox4-Nrf2 redox imbalance. Sci Transl Med. 2014;6(231): 231 ra247

34. Lehmann M, Mutze K, Schiller HB, Wagner DE, Konigshoff M: Increased alveolar epithelial cell senescence in pulmonary fibrosis. Am J Respir Crit Care Med 2016, 193

35. Lockey RF, Turn CS, Kolliputi N. Putting the brakes on age-related idiopathic pulmonary fibrosis: can Nox4 inhibitors suppress IPF? Exp Gerontol. 2015;63:81-2.

36. Minagawa S, Araya J, Numata T, Nojiri S, Hara H, Yumino Y, Kawaishi M, Odaka M, Morikawa T, Nishimura SL, et al. Accelerated epithelial cell senescence in IPF and the inhibitory role of SIRT6 in TGF-beta-induced senescence of human bronchial epithelial cells. Am J Physiol Lung Cell Mol Physiol. 2011;300(3):L391-401.

37. Yanai H, Shteinberg A, Porat Z, Budovsky A, Braiman A, Ziesche R, Fraifeld VE. Cellular senescence-like features of lung fibroblasts derived from idiopathic pulmonary fibrosis patients. Aging (Albany NY). 2015;7(9):664-72.

38. Schafer MJ, White TA, lijima K, Haak AJ, Ligresti G, Atkinson EJ, Oberg AL, Birch J, Salmonowicz H, Zhu Y, et al. Cellular senescence mediates fibrotic pulmonary disease. Nat Commun. 2017;8:14532.

39. Hohmann MS, Habiel DM, Coelho AL, Verri WA Jr, Hogaboam CM. Quercetin enhances ligand-induced apoptosis in senescent idiopathic pulmonary fibrosis fibroblasts and reduces lung fibrosis in vivo. Am J Respir Cell Mol Biol. 2019;60(1):28-40.

40. Mori M, Kida H, Morishita H, Goya S, Matsuoka H, Arai T, Osaki T, Tachibana I, Yamamoto S, Sakatani M, et al. Microsatellite instability in transforming growth factor-beta 1 type $\|$ receptor gene in alveolar lining epithelial cells of idiopathic pulmonary fibrosis. Am J Respir Cell Mol Biol. 2001;24(4):398-404.

41. Thomas AQ, Carneal J, Markin C, Lane KB, Phillips JA 3rd, Loyd JE. Allelic imbalance demonstrated by microsatellite analysis of lung samples from patients with familial pulmonary fibrosis. Chest. 2002;121(3 Suppl):25S.

42. Goto T, Maeshima A, Oyamada Y, Kato R. Idiopathic pulmonary fibrosis as a prognostic factor in non-small cell lung cancer. Int J Clin Oncol. 2014;19(2):266-73.

43. Lee T, Park JY, Lee HY, Cho YJ, Yoon HI, Lee JH, Jheon S, Lee CT, Park JS. Lung cancer in patients with idiopathic pulmonary fibrosis: clinical characteristics and impact on survival. Respir Med. 2014;108(10):1549-55.

44. Ferguson BJ, Mansur DS, Peters NE, Ren H, Smith GL. DNA-PK is a DNA sensor for IRF-3-dependent innate immunity. Elife. 2012;1:e00047.

45. Bailey SM, Brenneman MA, Halbrook J, Nickoloff JA, Ullrich RL, Goodwin EH. The kinase activity of DNA-PK is required to protect mammalian telomeres. DNA Repair (Amst). 2004:3(3):225-33.

46. Bracalente C, Ibanez IL, Molinari B, Palmieri M, Kreiner A, Valda A, Davidson $J$, Duran $\mathrm{H}$. Induction and persistence of large gammaH2AX foci by high linear energy transfer radiation in DNA-dependent protein kinase-deficient cells. Int J Radiat Oncol Biol Phys. 2013;87(4):785-94.

47. Goytisolo FA, Samper E, Edmonson S, Taccioli GE, Blasco MA. The absence of the dna-dependent protein kinase catalytic subunit in mice results in anaphase bridges and in increased telomeric fusions with normal telomere length and G-strand overhang. Mol Cell Biol. 2001;21(11):3642-51.

48. Lin YF, Shih HY, Shang Z, Matsunaga S, Chen BP. DNA-PKcs is required to maintain stability of Chk1 and Claspin for optimal replication stress response. Nucleic Acids Res. 2014:42(7):4463-73.

49. Liu S, Opiyo SO, Manthey K, Glanzer JG, Ashley AK, Amerin C, Troksa K, Shrivastav M, Nickoloff JA, Oakley GG. Distinct roles for DNA-PK, ATM and ATR in RPA phosphorylation and checkpoint activation in response to replication stress. Nucleic Acids Res. 2012:40(21):10780-94.

50. Venkatachalam G, Surana U, Clement MV. Replication stress-induced endogenous DNA damage drives cellular senescence induced by a sublethal oxidative stress. Nucleic Acids Res. 2017;45(18):10564-82. 
51. Linnoila RI. Functional facets of the pulmonary neuroendocrine system. Lab Investig. 2006;86(5):425-44.

52. Song H, Yao E, Lin C, Gacayan R, Chen MH, Chuang PT. Functional characterization of pulmonary neuroendocrine cells in lung development, injury, and tumorigenesis. Proc Natl Acad Sci U S A. 2012;109(43):17531-6.

53. Ito T, Ogura T, Ogawa N, Udaka N, Hayashi H, Inayama Y, Yazawa T,

Kitamura H. Modulation of pulmonary neuroendocrine cells in idiopathic interstitial pneumonia. Histol Histopathol. 2002;17(4):1121-7.

\section{Publisher's Note}

Springer Nature remains neutral with regard to jurisdictional claims in published maps and institutional affiliations.

Ready to submit your research? Choose BMC and benefit from:

- fast, convenient online submission

- thorough peer review by experienced researchers in your field

- rapid publication on acceptance

- support for research data, including large and complex data types

- gold Open Access which fosters wider collaboration and increased citations

- maximum visibility for your research: over $100 \mathrm{M}$ website views per year

At $\mathrm{BMC}$, research is always in progress.

Learn more biomedcentral.com/submissions 